\title{
Midline Watershed: Unusual Border-Zone Infarct of the Corpus Callosum
}

\section{Prakash Ambady', Swamy Venkatesh $\mathrm{Y}^{2 *}$ and Ambika Rao ${ }^{3}$}

${ }^{1}$ Department of Neurology (PA), Drexel University College of Medicine, Philadelphia, PA, USA

${ }^{2}$ Department of Neurology (YSV), University of South Carolina School of Medicine, Columbia, USA

${ }^{3}$ Department of Medicine (AR), Dorn VAMC, Columbia, SC, USA

\begin{abstract}
Ischemic lesions involving the Corpus Callosum (CC) are rare. Symptoms are nonspecific and clinical findings vary depending on the site and size of the lesions. We describe a rare case of watershed infarct involving the whole corpus callosum but sparing the more common border-zone infarcts between the anterior cerebral artery-middle cerebral artery and the middle cerebral artery posterior cerebral artery and review the relevant literature with special emphasis on the vascular anatomy of the corpus callosum.
\end{abstract}

Keywords: Corpus callosum; Hypercholesterolemia; Exotropia

\section{Case Report}

46-year-old man with diabetes, hypertension, hypercholesterolemia, and end stage renal disease presented with acute confusion. His BP was noted to be $60 / 28 \mathrm{~mm} \mathrm{Hg}$. He opened his eyes to verbal commands. Right pupil was $5 \mathrm{~mm}$ and the left pupil $4.5 \mathrm{~mm}$, both reactive to light. Exotropia and hypotropia of the right eye, and roving eye movements were noted. He withdrew all rxtremities to pain. DTR's were noted as $3 / 4$ in the left upper and 2/4 in the right upper limbs, and absent in the lower limbs. Babinski's sign was absent. MRI of the brain showed hyper intensity involving the entire corpus callosum on DWI (Figures 1 and 2). MRA showed stenosis of the proximal A1 segment of the right ACA at its bifurcation with a hypoplastic right PCA (Figure 3). The patient subsequently had a pulseless electrical activity code and died.

\section{Discussion}

Infarcts of the corpus callosum are uncommon and are attributed to a rich blood supply from three main arterial systems: The anterior communicating artery, the pericallosal artery and the posterior pericallosal artery $[1,2]$. The pericallosal branches of the Anterior Cerebral Artery (ACA) supply the major portion of the body of the CC. Perforating branches of the ACA supplies the rostrum and genu [3]. The pericallosal branch may reach as far back as the foramen of Monro. It gives rise to four branches: the callosal, cingulo callosal, long callosal, and recurrent callosal arteries [4-5]. There are 3 to 23 cingulo callosal arteries per hemisphere that supply anterior parts of the corpus callosum; and form abundant anastomoses.

The splenium of the CC is supplied by the posteror callosal branch of the Posterior cerebral artery (PCA) or the splenic artery. They take

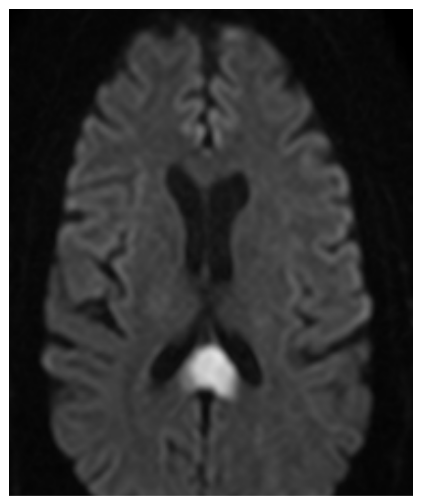

Figure 1: DWI showing infarct of the splenium of the corpus callosum off perpendicularly from the PCA [1,6,7]. An accessory posterior pericallosal artery has been described [6]. Anastomosis of the ACA and PCA branches occurs at the tip of the splenium in $75 \%$ to $100 \%$ of the cases $[7,8]$.

The anterior communicating artery also supplies the CC $[3,9]$. The subcallosal artery provides blood supply to the medial portions of the rostrum and genu of the CC. The median callosal branches supply the rostrum, genu, and body of the CC and medial aspect of the frontal and parietal lobes $[1,10]$. The perpendicular origins of the pericallosal vessels make it difficult for the emboli to enter these vessels. Unusual features include arteriole-venule pairs, perivascular fibrous alae, and recurrent companion arterioles, providing resistance to atherosclerosis [10]. Pericallosal pial plexus also adds stability $[4,11-$ 13]. Chrysikopoulos et al. described only three diffuse lesions involving the genu and body of the CC [1]. The splenium was the most common site followed by the body and genu. This can be explained by the fact that the final anastomosis between the ACA and PCA occurs at the tip

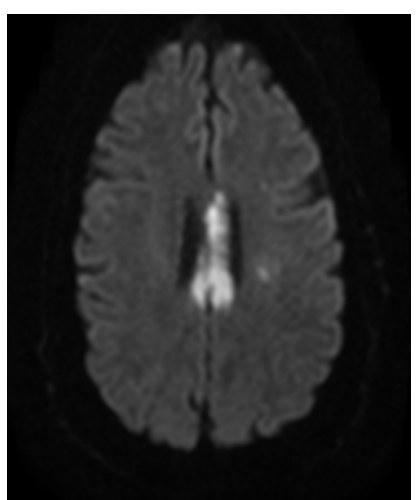

Figure 2: DWI showing infarct of the corpus callosum.

*Corresponding author: Swamy Venkatesh Y, University of South Carolina School of Medicine, 8 Medical Park, 420, Columbia, SC 29203, USA, Tel: 803-5456050; Fax: 803-545-6051; E-mail: Y.Venkatesh@uscmed.sc.edu

Received September 25, 2014; Accepted October 17, 2014; Published October 21,2014

Citation: Ambady P, Venkatesh YS, Rao A (2014) Midline Watershed: Unusual Border-Zone Infarct of the Corpus Callosum. J Clin Case Rep 4: 435 doi:10.4172/2165-7920.1000435

Copyright: ( $) 2014$ Ambady P, et al. This is an open-access article distributed under the terms of the Creative Commons Attribution License, which permits unrestricted use, distribution, and reproduction in any medium, provided the original author and source are credited. 
Citation: Ambady P, Venkatesh YS, Rao A (2014) Midline Watershed: Unusual Border-Zone Infarct of the Corpus Callosum. J Clin Case Rep 4: 435. doi:10.4172/2165-7920.1000435

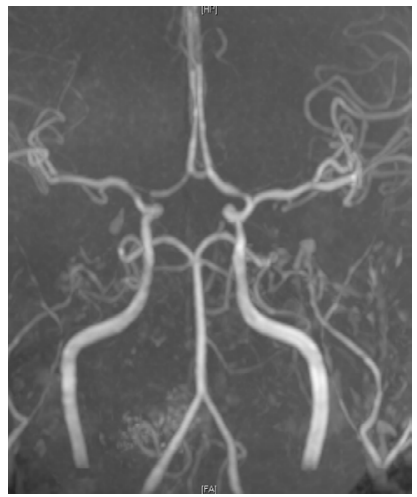

Figure 3: MRA showing stenosis of the proximal right ACA.

of the splenium. Anatomical-clinical correlations are challenging. In most cases, infarcts occur simultaneously in other arterial distributions. A hypoplastic A1 segment may facilitate occurrence of embolism in the anterior cerebral artery distribution [3]. In the described case the stenosis noted in the ACA on MRA along with the hypoplastic PCA may have played a predisposing role in the presence of hypotension.

\section{Conclusion}

Border-zone infarcts involving the whole corpus callosum are rare because of its relative resistance to small-vessel disease and extensive vascular anastomoses [2,14-18]. Certain circumstances including isolated stenosis of arteries and systemic hypotension can precipitate this unusual watershed infarct. Understanding the vascular anatomy of the CC is the key to diagnosis.

\section{References}

1. Chrysikopoulos H, Andreou J, Roussakis A, Pappas J (1997) Infarction of the corpus callosum: computed tomography and magnetic resonance imaging. Eur J Radiol 25: 2-8.

2. Kasow DL, Destian S, Braun C, Quintas JC, Kagetsu NJ, et al. (2000) Corpus callosum infarcts with atypical clinical and radiologic presentations. AJNR Am J Neuroradiol 21: 1876-1880.

3. Kazui S, Sawada T, Naritomi H, Kuriyama Y, Yamaguchi T (1993) Angiographic evaluation of brain infarction limited to the anterior cerebral artery territory. Stroke 24: 549-553.

4. Spengos K, Tsivgoulis G, Chatziioannou A, Potagas C, Zakopoulos N, et al. (2006) Extensive corpus callosum infarction: an uncommon pattern of watershed ischaemia? J Neurol 253: 1646-1648

5. Perlmutter D, Rhoton AL Jr (1978) Microsurgical anatomy of the distal anterior cerebral artery. J Neurosurg 49: 204-228.

6. Ture U, Yaşargil MG, Krisht AF (1996) The arteries of the corpus callosum: a microsurgical anatomic study. Neurosurgery 39: 1075-1084.

7. Zeal AA (1980) Microsurgical anatomy of the posterior cerebral artery: Introduction to Cerebral Angiography. ( $2^{\text {nd }}$ edn), Lippincott Williams and Wilkins, USA.

8. Milisavljevic M, Marinkovic S, Lolić-Draganic V, Djordjevic L (1986)Anastomoses in the territory of the posterior cerebral arteries. Acta Anat (Basel) 127: 221-225

9. Baptista AG (1963) Studies on the arteries of the brain. ii. the anterior cerebral artery: some anatomic features and their clinical implications. Neurology 13: 825-835.

10. Moody DM, Bell MA, Challa VR (1988) The corpus callosum, a unique whitematter tract: anatomic features that may explain sparing in Binswanger disease and resistance to flow of fluid masses. AJNR Am J Neuroradiol 9: 1051-1059.

11. Malobabic S, Puskas L, Bogdanovi D, Jasovicł A (1989) Anatomy of the pericallosal pial plexus in man. Anat Anz 169: 125-130.

12. Hang YP, Wolf BS (1964) Angiographic features of the pericallosal cistern Radiology 82: 14-23.

13. Gean-Marton AD, Vezina LG, Marton KI, Stimac GK, Peyster RG, et al. (1991) Abnormal corpus callosum: a sensitive and specific indicator of multiple sclerosis. Radiology 180: 215-221.

14. Giroud M, Dumas R (1995) Clinical and topographical range of callosal infarction: a clinical and radiological correlation study. J Neurol Neurosurg Psychiatry 59: 238-242.

15. Kumral E, Kocaer T, Sagduyu A, Sirin H, Toygar A, et al. (1995) Callosal infarction after bilateral occlusion of the internal carotid arteries with hemineglect syndrome and astasia-abasia. Rev Neurol (Paris) 151: 202-205.

16. Garcia-Monco JC, Cortina IE, Ferreira E, Martínez A, Ruiz L, et al. (2011) Reversible splenial lesion syndrome (RESLES): what's in a name? J Neuroimaging 21: e1-14.

17. Pandian JD, Henderson RD (2005) "Boomerang sign" in the splenium of the corpus callosum. Med J Aust 183: 628.

18. Critchley M (1930) Syndromes of the Anterior Cerebral Artery. Proc R Soc Med 23: $630-632$. 